\title{
Uraemic Pruritus: Relief of Itching by Gabapentin and Pregabalin
}

\author{
Hugh Rayner Jyoti Baharani Steve Smith Vijayan Suresh Indranil Dasgupta
}

Heart of England NHS Foundation Trust, Birmingham, UK

\author{
Key Words \\ Uraemia · Pruritus · Itch · Gabapentin · Pregabalin · Dialysis . \\ Chronic kidney disease
}

\begin{abstract}
Background: Pruritus (skin irritation or itching) is common in patients with chronic kidney disease (CKD) stages 4 and 5. It is associated with disrupted sleep, reduced quality of life, depression and increased mortality. A video of a patient describing the symptoms is at vimeo.com/49458473. Methods: We used gabapentin or pregabalin in 71 consecutive patients, $82 \%$ male. 25 had CKD stage 4 or 5 , median eGFR $=17$, range $9-30 ; 40$ were on haemodialysis; 6 on peritoneal dialysis. Median itch severity score out of $10=8$, range 6-10; median duration of itching $=6$ months, range $0.5-240$. Serum calcium $\leq 2.60 \mathrm{mmol} / \mathrm{l}(\leq 10.4 \mathrm{mg} / \mathrm{dl})$ in $87 \%$ patients, phosphate $\leq 1.8 \mathrm{mmol} / \mathrm{l}$ ( $\leq 5.6 \mathrm{mg} / \mathrm{dl}$ ) in $75 \% .63 \%$ had used antihistamines and not gained relief. Starting dose of gabapentin $100 \mathrm{mg}$ after dialysis or daily. Patients intolerant of gabapentin were offered pregabalin, starting dose $25 \mathrm{mg}$ after dialysis or daily. Results: Gabapentin relieved itching in 47 patients (66\%). A video of a patient describing the effect is at vimeo.com/49455976. 26 patients (37\%) suffered side effects from gabapentin. Of 21 patients who stopped gabapentin due to side effects, 16 started pregabalin. Pregabalin relieved itching in 13 patients (81\%). In total, gabapentin or pregabalin relieved itching in 60 patients (85\%), median follow-up 2 months (range 1-8 months). Median
\end{abstract}

itch severity out of 10 reduced from 8 to 1 . Conclusions: Gabapentin or pregabalin relieved itching in $85 \%$ of 71 consecutively treated CKD patients. Patients should be advised about side effects and the drug initiated at a low dose. Patients intolerant of gabapentin may tolerate pregabalin.

Copyright $\odot 2013$ S. Karger AG, Basel

\section{Introduction}

Pruritus (skin irritation or itching) is common in patients with chronic kidney disease (CKD) stages 4 and 5. For many patients, the symptoms are much more than intermittent irritations relieved by a satisfying scratch. $32 \%$ of haemodialysis (HD) patients are moderately or very much bothered by itchiness and $10 \%$ extremely bothered [1]. HD patients with moderate or severe itch are significantly more likely to feel drained or depressed and have a $17 \%$ higher mortality risk [1], statistically associated with the quality of sleep [1]. A patient's description of these symptoms and their impact is at vimeo. com/49458473.

HD patients with itching and pain due to diabetic neuropathy were found to be relieved of both symptoms by gabapentin $[2,3]$. This suggests that GABA-dependent $\mathrm{C}$-terminal afferent nerve fibres mediate uraemic pruritus. Gabapentin is an analogue of the inhibitory neurotransmitter gaba-aminobutyric acid, GABA. Pregabalin $\left(\right.$ Lyrica $\left.{ }^{\circledR}\right)$ is a similar, more potent drug. They are

\section{KARGER}

E-Mail karger@karger.com

www.karger.com/nec
(C) 2013 S. Karger AG, Basel

$1660-2110 / 13 / 1224-0075 \$ 38.00 / 0$
Dr. Hugh C. Rayner

Heart of England NHS Foundation Trust Bordesley Green East

Birmingham B9 5SS (UK)

E-Mail hugh.rayner@heartofengland.nhs.uk 
mainly used in the treatment of epilepsy and neuropathic pain. They are eliminated by renal excretion as unchanged drug. Common side effects include dizziness and drowsiness.

A randomised double-blind placebo controlled crossover trial of gabapentin in $25 \mathrm{HD}$ patients aged 32-77 years showed a dramatic reduction in the severity of itch [2]. Similar results in HD patients have been reported in two subsequent trials $[4,5]$ and a small case series [3]. There have been two reports of relief of renal itch with pregabalin $[6,7]$.

We report our experience of using gabapentin and pregabalin to treat pruritus in a cohort of patients with CKD stages 4 and 5 from a wide age range, including those receiving peritoneal dialysis and $\mathrm{HD}$.

\section{Methods}

The Heart of England NHS Foundation Trust provides nephrology services to the population of approximately 800,000 in East Birmingham and the surrounding area. This is a socioeconomically and ethnically diverse community. In December 2012, the service was treating 407 patients on $\mathrm{HD}$ and 47 on peritoneal dialysis. 450 patients were receiving care for CKD stages 4 and 5 prior to renal replacement therapy. Subjects with itching were identified during routine consultations.

Itch severity was assessed before treatment using a scale ranging from 0 to 10 where 10 was the most severe itch imaginable. Patients whose itching was sufficiently troublesome, persistent and unrelieved by simple emollients or antihistamines were offered gabapentin treatment. Patients were advised that gabapentin was not licenced in the UK for this indication and were warned of possible side effects, particularly drowsiness. Patient gave verbal consent to be included in this report.

Gabapentin was started at $100 \mathrm{mg}$ once daily for CKD and peritoneal dialysis (PD) patients and at $100 \mathrm{mg}$ after dialysis for HD patients. Patients adjusted the dose regimen according to their symptoms in collaboration with their physician. Verbatim descriptions of quality of life before and during gabapentin treatment were noted. One patient gave written consent for an interview to be video recorded and made available via the Internet.

Patients who were unable to continue gabapentin due to side effects were offered pregabalin, starting at $25 \mathrm{mg}$ once daily for $\mathrm{CKD}$ and $\mathrm{PD}$ patients and $25 \mathrm{mg}$ after dialysis for HD patients.

Patients were prescribed gabapentin or pregabalin as an open label drug. There was no placebo or control group.

\section{Results}

Results on 71 consecutive patients with severe itching (score $\geq 6 / 10$ ) started on gabapentin since February 2012 are presented. Itching had been present for a median of 6 months. Patients were severely affected by itching, $87 \%$ having sleep disturbance and $66 \%$ making themselves bleed from scratching. Details of their demographics, symptoms, previous treatment, dosage and response to gabapentin are given in table 1.

$63 \%$ had tried antihistamines with limited or no effect. One had gained no benefit from a course of UV therapy. The majority had serum calcium (corrected for serum albumin) and phosphate levels below the upper limit of recommended ranges $(87 \%$ calcium $<2.60 \mathrm{mmol} / \mathrm{l},<10.4$ $\mathrm{mg} / \mathrm{dl} ; 75 \%$ phosphate $<1.8 \mathrm{mmol} / \mathrm{l},<5.6 \mathrm{mg} / \mathrm{dl})$.

$47(66 \%)$ gained relief of itch from gabapentin. Median itch severity was 1 (range $0-6$ ) after median treatment duration of 2 months (range 1-8).

The following are verbatim reports from patients whose itching was relieved:

'You prescribed gabapentin and she took one $100 \mathrm{mg}$ capsule on Friday evening after dialysis. She felt drowsy after half an hour and then had the most remarkable 2 days of relief from the itching I have seen for many years. On Monday some symptoms re-appeared... she [took] another capsule [on] Monday evening after dialysis. The relief was the same, with another peaceful and undisturbed night's sleep (for both of us!). We cannot thank you enough for prescribing this medicine. It has given $\mathrm{E}$ peace of mind, the strain has dropped from her face and she is much more positive about her condition and treatment.' Patient E.

They are 'magic pills'. I'm a 'new man'. 'Let other people who suffer from itching try this.' Patient D.

'After $2 \mathrm{~h}$ the itching went off like a light switch.' 'I am a different man.' Patient J.

'I'm still itching in the mornings when I get up but once I have my tablet of gabapentin I stop itching for the rest of the day, until late evening and perhaps once during the night. But Wow I've been catching up on my sleep! Therefore, I have had so much more energy during the day and feel my depression lifting!' Patient V.

'I have found I need to take a tablet during the weekend later Saturday or Sunday morning as the itching starts to return so a dosage of $100 \mathrm{mg} 4$ times weekly seems appropriate for me. I do notice that towards the end of the dialysis session I am starting to itch so glad to take the tablet once the session has ended.' Patient N.

A video of one patient's experience of using gabapentin can be seen at vimeo.com/49455976.

Twenty-six patients (37\%) suffered side effects from gabapentin: over-sedation (12), dizziness (6), tight chest/ breathlessness (3), shaking limbs (2), vomiting (2), blotchy rash (2), nightmares (1), cramps (1), hair loss (1), low BP (1), incontinence (1); some patients had multiple side effects. 24 (34\%) stopped gabapentin: 3 due to lack of effect on itching, 21 due to side effects.

Of the 21 who stopped gabapentin due to side effects, 16 were treated with pregabalin (table 2). 13 (81\%) gained 
Table 1. Details of patients treated with gabapentin

\begin{tabular}{|c|c|c|c|}
\hline Gabapentin & CKD & $\mathrm{HD}$ & $\mathrm{PD}$ \\
\hline Number of patients & 25 & 40 & 6 \\
\hline $\mathrm{M}: \mathrm{F}$ & $15: 10$ & $31: 9$ & $6: 0$ \\
\hline Age, median (range), years & $74(33-90)$ & $64(35-88)$ & $65(42-80)$ \\
\hline eGFR, median (range), $\mathrm{ml} / \mathrm{min} / 1.73 \mathrm{~m}^{2}$ & $17(9-30)$ & N/A & $\mathrm{N} / \mathrm{A}$ \\
\hline Duration of RRT, median (range), months & N/A & $22(1-324)$ & $15(5-88)$ \\
\hline Serum Ca, albumin-corrected, median (range), mg/dl, mmol/l & $\begin{array}{l}9.44(8.60-10.48) \\
2.36(2.15-2.62)\end{array}$ & $\begin{array}{l}9.78(7.16-11.52) \\
2.45(1.79-2.88)\end{array}$ & $\begin{array}{l}10.32(9.36-10.40) \\
2.59(2.34-2.68)\end{array}$ \\
\hline Serum phosphate, median (range), mg/dl, mmol/l & $\begin{array}{l}4.37(3.00-6.04) \\
1.41(0.97-1.95)\end{array}$ & $\begin{array}{l}4.75(2.2-8.85) \\
1.54(0.71-2.86)\end{array}$ & $\begin{array}{l}4.58(2.91-5.73) \\
1.49(0.94-1.86)\end{array}$ \\
\hline PTH, median (range), pg/ml & $213(27-509)$ & $230(3-1166)$ & $472(14-713)$ \\
\hline Duration of itching, median (range), months & $7(2-72)$ & $6(0.5-240)$ & $2(1-30)$ \\
\hline Severity of itch, median $(\max =10)$ & $8(6-10)$ & $9(6-10)$ & $8(7-10)$ \\
\hline Sleep disturbance, yes (\%) & $21(84 \%)$ & $35(88 \%)$ & $6(100 \%)$ \\
\hline Bleeding from scratching, yes $(\%)$ & $15(60 \%)$ & $26(65 \%)$ & $6(100 \%)$ \\
\hline Previous antihistamines, yes (\%) & $19(76 \%)$ & $23(58 \%)$ & $3(50 \%)$ \\
\hline $\begin{array}{l}\text { Itch response: (1) side effects, gabapentin stopped } \\
\text { (2) no reduction of itch, gabapentin stopped } \\
\text { (3) significant reduction of itch: } n\end{array}$ & $10: 2: 13$ & $8: 1: 31$ & $3: 0: 3$ \\
\hline Final dose of gabapentin & $\begin{array}{l}13 @ 100 \text { mg o.d. } \\
4 @ 100 \text { mg b.d. } \\
5 @ 200 \text { mg o.d. } \\
2 @ 300 \text { mg o.d. } \\
\text { (1 missing) }\end{array}$ & $\begin{array}{l}\text { 13@100 mg after dialysis } \\
2 @ 300 \mathrm{mg} \text { after dialysis } \\
1 @ 400 \mathrm{mg} \text { after dialysis } \\
11 @ 100 \mathrm{mg} \text { daily } \\
6 @ 200 \mathrm{mg} \text { daily } \\
5 @ 300 \mathrm{mg} \text { daily } \\
1 @ 400 \mathrm{mg} \text { daily } \\
1 @ 900 \mathrm{mg} \text { daily }\end{array}$ & $\begin{array}{l}\text { 3@100 mg o.d. } \\
1 @ 200 \text { mg o.d. } \\
1 @ 300 \text { mg o.d. } \\
1 @ 200 \text { mg } 2 \text { weekly }\end{array}$ \\
\hline Length of follow-up, median (range), months, & $1(1-4)$ & $2.5(1-8)$ & $1(1-5)$ \\
\hline
\end{tabular}

Table 2. Details of patients treated with pregabalin

\begin{tabular}{|c|c|c|c|}
\hline Pregabalin & CKD & HD & $\mathrm{PD}$ \\
\hline Number of patients & 6 & 6 & 3 \\
\hline $\begin{array}{l}\text { Itch response: (1) side effects, pregabalin stopped (2) no reduction } \\
\text { of itch, pregabalin stopped (3) significant reduction of itch: } n\end{array}$ & $1: 1: 4$ & $0: 0: 6$ & $0: 0: 3$ \\
\hline Final dose of pregabalin & $\begin{array}{l}\text { 2@25 mg o.d. } \\
1 @ 50 \text { mg o.d. } \\
\text { 2@75 mg o.d. } \\
1 @ 75 \text { mg b.d. }\end{array}$ & $\begin{array}{l}1 @ 25 \text { mg after dialysis } \\
2 @ 25 \text { mg o.d. } \\
3 @ 50 \text { mg o.d. }\end{array}$ & $\begin{array}{l}1 @ 25 \text { mg o.d. } \\
1 @ 25 \text { mg b.d. } \\
1 @ 50 \text { mg o.d. }\end{array}$ \\
\hline Length of follow-up, median (range), months & $1(1-4)$ & $2(1-4)$ & $2(1-3)$ \\
\hline
\end{tabular}

relief of itch from pregabalin. Median itch severity was 2 (range 0-5) after median treatment duration of 2.5 months (range 1-4). 3 stopped pregabalin: 1 due to lack of effect on itching, 2 due to side effects (oversedation in both).

Gabapentin and Pregabalin Relieve Renal Itch
Combining both treatments, 60 of the 71 patients (85\%) gained significant relief of their itch and continued taking the tablets. For most, the effect was noticeable after taking the first one or two doses or after an increase in dose. 
No significant attenuation of the effect was reported. Two patients' itching returned when gabapentin was stopped because of supply problems; restarting it relieved the itching again. Four patients stopped taking gabapentin or pregabalin and remained free of itch.

Relief of itch was achieved in some patients with skin conditions associated with itching. One had pruritus nodularis and 2 had chronic idiopathic urticaria. One patient with chronic eczema on the head and neck gained complete relief of itching on the limbs and partial relief in eczematous regions.

Six patients had improvement in pain conditions. Peripheral neuropathic pain was relieved in 3 patients, severe headaches and neck pain improved in 1 and joint pains and phantom limb pain improved in 1 each.

\section{Discussion}

This is the largest cohort study to date on the use of gabapentin and pregabalin to treat severe itching in a population of patients with CKD stage 4 and 5, including those on HD and PD.

Healthcare professionals may underestimate the impact of itching on the lives of some patients with CKD. The unremitting symptoms stop the patient from relaxing or sleeping. Patients and their partners become drained and depressed. Two patients' lives were so affected by itch that they considered stopping HD: 'It controls my life; it drives me mad.' A vivid description by one affected patient is at vimeo.com/49458473.

Itching is commonly attributed to high levels of serum calcium or phosphate. This can lead to a focus on intensifying diet and phosphate binders to treat itch. Our experience confirms data from the DOPPS showing that the mean values in patients with moderate or severe itch were only very slightly increased, 0.25 and $0.04 \mathrm{mg} / \mathrm{dl}$ $(0.08$ and $0.01 \mathrm{mmol} / \mathrm{l})$, respectively [1]. The association with high serum calcium and phosphate may not be causal.

The marked male predominance of patients with itch in this series (82\%) is consistent with the DOPPS study of HD patients [1]. It is not known why males are more affected.

The available treatments for uraemic pruritus have been recently reviewed in detail [8]. Antihistamines are commonly used based upon their effect on urticarial itch. However, there have been no well-conducted randomised controlled trials of antihistamines for renal itch. Anecdotal experience indicates that they are rarely if ever effective apart from their mild sedative effect. The patients' description of renal itch differs from histaminemediated urticaria; renal itch is felt below the surface of the skin.

Gabapentin also has been shown to relieve itching in controlled trials involving patients with itch due to burns and IL-2 treatment $[9,10]$ but not cholestasis [11].

In the current prospective study of 71 consecutively treated patients, $85 \%$ of patients treated with gabapentin or pregabalin gained substantial or complete relief from their itching whilst taking the drug. As this was not a randomised placebo-controlled study, it cannot be proved that the drug was responsible for the effects reported. However, the degree of reduction in itch was consistent with previous placebo-controlled trials. Furthermore, patients reported a clear dose-response relationship between gabapentin/pregabalin and itch severity and titrated their treatment according to the response. Four patients stopped the drug without the itch returning, consistent with marked fluctuation in the severity of itching week-to-week in some patients described in a detailed longitudinal study [12].

In the current study, $30 \%$ of patients experienced significant side effects with gabapentin and $12 \%$ with pregabalin, most commonly oversedation. It was not possible to predict which patients would suffer side effects. In the previous randomised trial of gabapentin [3] side effects were mild to moderate and usually subsided within 7 days. None of the patients in that trial dropped out. Patients in our study may have been more prone to adverse effects due to greater age and comorbidity.

Gabapentin and pregabalin should be started cautiously with close feedback between physician and patient. We routinely started with $100 \mathrm{mg}$ gabapentin after dialysis for HD patients or once daily at night in CKD and PD patients. Others have also found this to be a more appropriate starting dose than the $300 \mathrm{mg}$ used in the original RCT $[4,5]$. The starting dose of pregabalin was 25 $\mathrm{mg}$. The effects of the drug were noticed after one or a few doses, allowing rapid dose adjustment. Patients should be warned about possible sedation and dizziness. Patients with mobility difficulties or at risk of falls should be supervised for at least 12-24 h after the first dose.

Some patients had pain syndromes as well as itch and gained relief of both symptoms. Relief of itch by gabapentin in patients with peripheral neuropathic pain was the clue that led Gunal et al. [2] to carry out the initial randomised controlled trial. A recent study has shown similar relief of itch and pain with gabapentin and pregablin in HD patients [7]. 
Many patients reported improved sleep quality and mood, beyond that due to the relief of itching. This is consistent with the demonstration of improved sleep quality and reduction in depression due to gabapentin and pregabalin in HD patients with neuropathic pain [13].

\section{Conclusions}

Clinicians should enquire about skin irritation and itching during consultations. Patients may be reluctant to admit to these symptoms due to embarrassment or a belief that they are caused by non-adherence to diet or phosphate binder therapy.

In patients with CKD and itching that persists despite attempts to correct calcium and phosphate balance and treatment with emollient creams, gabapentin is the drug of first choice based upon the results of a controlled trial [2]. Pregabalin may be effective in patients unable to tolerate gabapentin.

These treatments should be promoted widely amongst the kidney community so that affected patients can be relieved of this distressing and debilitating symptom.

\section{Acknowledgements}

The authors thank nursing staff in the HEFT nephrology service for identifying patients affected by itch: R. Adkins, M. Barrett, A. Dodds, C. Rayney and C. Richardson.

\section{Disclosure Statement}

There are no financial conflicts of interest to declare. The authors received no financial support for this study.

\section{References}

1 Pisoni RL, Wikstrom B, Elder SJ, Akizawa T, Asano Y, Keen ML, Saran R, Mendelssohn DC, Young EW, Port FK: Pruritus in haemodialysis patients: international results from the Dialysis Outcomes and Practice Patterns Study (DOPPS). Nephrol Dial Transplant 2006;21:3495-3505.

-2 Gunal AI, Ozalp G, Yoldas TK, Gunal SY, Kirciman E, Celiker H: Gabapentin therapy for pruritus in haemodialysis patients: a randomized, placebo-controlled, double-blind trial. Nephrol Dial Transplant 2004;19:31373139.

-3 Manenti L, Vaglio A, Costantino E, Danisi D, Oliva B, Pini S, Prati E, Testori A: Gabapentin in the treatment of itch: an index case and a pilot evaluation. J Nephrol 2005; 18 : 86-91.

4 Naini AE, Harandi AA, Khanbabapour S, Shahidi S, Seirafiyan S, Mohseni M: Gabapentin: a promising drug for the treatment of uremic pruritus. Saudi J Kidney Dis Transpl 2007;18:378-381.
5 Razeghi E, Eskandari D, Ganji MR, Meysamie AP, Togha M, Khashayar P: Gabapentin and uremic pruritus in hemodialysis patients. Ren Fail 2009;31:85-90.

-6 Aperis G, Paliouras C, Zervos A, Arvanitis A, Alivanis $P$ : The use of pregabalin in the treatment of uraemic pruritus in haemodialysis patients. J Ren Care 2010;36:180-185.

7 Solak Y, Biyik Z, Atalay H, Gaipov A, Guney F, Turk S, Covic A, Goldsmith D, Kanbay M: Pregabalin versus gabapentin in the treatment of neuropathic pruritus in maintenance hemodialysis patients: a prospective crossover study. Nephrology (Carlton) 2012;17:710-717.

$\checkmark 8$ Manenti L, Tansinda P, Vaglio A: Uraemic pruritus. Clinical characteristics, pathophysiology and treatment. Drugs 2009;69:251-263.

-9 Ahuja RB, Gupta R, Gupta G, Shrivastava P: A comparative analysis of cetirizine, gabapentin and their combination in the relief of postburn pruritus. Burns 2011;37:203-207.
10 Lee SH, Baig M, Rusciano V, Dutcher JP: Novel management of pruritus in patients treated with IL-2 for metastatic renal cell carcinoma and malignant melanoma. J Immunotherapy 2010;33:1010-1013.

11 Bergasa NV, McGee M, Ginsburg IH, Engler D: Gabapentin in patients with the pruritus of cholestasis: a double-blind, randomized, placebo-controlled trial. Hepatology 2006;44: 1317-1323.

12 Mathur VS, Lindberg J, Germain M, Block G, Tumlin J, Smith M, Grewal M, McGuire D, ITCH National Registry Investigators: A longitudinal study of uremic pruritus in hemodialysis patients. Clin J Am Soc Nephrol 2010;5: 1410-1419.

13 Biyik Z, Solak Y, Atalay H, Gaipov A, Guney F, Turk S: Gabapentin versus pregabalin in improving sleep quality and depression in hemodialysis patients with peripheral neuropathy: a randomized prospective crossover trial Int Urol Nephrol 2012, DOI 10.1007/s11255012-0193-1. 